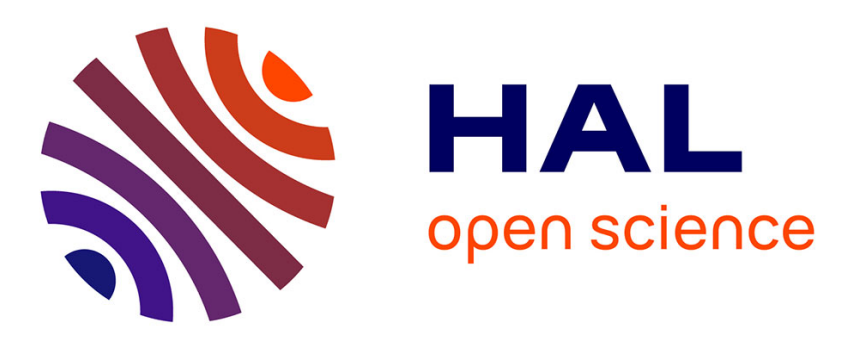

\title{
Receptor kinase signalling in plants and animals: distinct molecular systems with mechanistic similarities
}

J. Mark Cock, Vincent Vanoosthuyse, Thierry Gaude

\section{To cite this version:}

J. Mark Cock, Vincent Vanoosthuyse, Thierry Gaude. Receptor kinase signalling in plants and animals: distinct molecular systems with mechanistic similarities. Current Opinion in Cell Biology, 2002. hal-01926798

\section{HAL Id: hal-01926798 \\ https://hal.science/hal-01926798}

Submitted on 18 Dec 2020

HAL is a multi-disciplinary open access archive for the deposit and dissemination of scientific research documents, whether they are published or not. The documents may come from teaching and research institutions in France or abroad, or from public or private research centers.
L'archive ouverte pluridisciplinaire HAL, est destinée au dépôt et à la diffusion de documents scientifiques de niveau recherche, publiés ou non, émanant des établissements d'enseignement et de recherche français ou étrangers, des laboratoires publics ou privés. 


\title{
Receptor kinase signalling in plants and animals: Distinct molecular systems with mechanistic similarities
}

\author{
J. Mark Cock, Vincent Vanoosthuyse, Thierry Gaude
}

Plant genomes encode large numbers of receptor kinases that are structurally related to the tyrosine and serine/threonine families of receptor kinase found in animals. Here we describe recent advances in the characterisation of several of these plant receptor kinases at the molecular level including the identification of receptor complexes, small polypeptide ligands and cytosolic proteins involved in signal transduction and receptor down-regulation. Phylogenetic analysis indicates that plant receptor kinases have evolved independently of the receptor kinase families found in animals. This hypothesis is supported by functional studies which have revealed differences between receptors kinase signalling in plants and animals, particularly concerning their interactions with cytosolic proteins. Despite these dissimilarities, however, plant and animal receptor kinases share many common features such as their single membrane-pass structure, their inclusion in membrane-associated complexes, the involvement of dimerisation and trans-autophosphorylation in receptor activation and the existence of inhibitors and phosphatases that down-regulate receptor activity. These points of convergence may represent features that are essential for a functional receptor kinase signalling system.

\section{Addresses}

Reproduction et Développement des Plantes, UMR 5667 CNRS-INRA-ENSL-UCBL, Ecole Normale Supérieure de Lyon, 46 allée d'Italie, 69364 Lyon Cedex 07, France Tel: 33472728611 
Fax: 33472728600

e-mail: Mark.Cock@ens-lyon.fr

\author{
Abbreviations \\ EGFR epidermal growth factor receptor \\ KAPP kinase associated protein phosphatase \\ LRR leucine-rich repeat \\ PRK plant receptor kinase \\ RTK receptor tyrosine kinase \\ RSK receptor serine/threonine kinase \\ $S$ locus $\quad$ self-incompatibility locus
}

\title{
Introduction - the receptor kinase gene superfamilies in plants and animals
}

One of the surprising observations that has recently come out of genome sequencing projects is that plant genomes are predicted to encode large numbers of receptor kinases with a eukaryotic-type kinase domain. Arabidopsis thaliana, for example, possesses 417 genes of this type [1**]. Until recently, these genes have been referred to as receptor-like kinases [2] but, based on the recent identification of several ligands that bind specifically to receptors of this family (see below), here we propose to use the term plant receptor kinase (PRK).

The structure of PRKs, which consist of an extracellular domain, a single membrane spanning domain and a cytosolic kinase domain, resembles those of the receptor tyrosine kinases (RTKs) and serine/threonine receptor kinases of the TGF $\beta \mathrm{R}$ family (RSKs) in metazoans. However, although PRKs are phylogenetically more closely related to these two families of animal receptor kinase than they are to other 
kinase families, each of these three classes of receptor kinase can be grouped into a distinct, monophyletic family ([1**]; Figure 1). Moreover, so far PRKs have been found exclusively in plants whereas RTKs and RSKs have been found almost exclusively in the metazoan lineage and no receptor kinases belonging to these families have been found in the genomes of unicellular eukaryotes such as yeast [3]. Taken together, these data suggest that receptor kinases have evolved independently in the two kingdoms, their appearance during evolution perhaps coinciding with the acquisition of muticellularity. This would be consistent with the currently accepted hypothesis that plants and animals have evolved multicellularity independently from distinct unicellular ancestors [4].

Remarkably, considering the evolutionary history of receptor kinases in plants and animals, recent studies suggest that they function, to a certain extent, in an analogous manner at the biochemical level, indicating convergent evolution. The aim of this review is to describe recent advances in the characterisation of PRK function and to compare these receptor kinases with their counterparts in animals.

\section{Structures and functions of plant receptor kinases}

A common feature of the receptor kinase families in plants and animals is that, whilst the kinase domains are homologous, the extracellular domains can be highly diverse indicating that different protein domains have been recruited to function as extracellular domains in each family. The PRK superfamily includes receptors with more than 20 structurally distinct extracellular domains, the most common including domains with leucine-rich repeats (LRRs), S domains (homologous to the $S$ [self-incompatibility] locus glycoprotein), domains with epidermal growth factor repeats and lectin domains $[1 * *, 5]$ 
Functional analyses, using both mutagenesis and transgenic approaches, have shown that PRKs are involved in the regulation of a wide range of developmental processes. One of the first PRKs to be identified, the $S$ locus receptor kinase (SRK), functions as the female component of self-incompatibility in Brassica, permitting the recognition and rejection of self pollen on the stigmas of self-incompatible plants [6,7]. Another PRK, CLAVATA1 (CLV1), is involved in the maintenance of the apical meristem in Arabidopsis and is part of a regulatory feedback loop that also includes the homeodomain-containing transcription factor WUSCHEL $\left[8^{* *}, 9^{*}, 10^{*}\right]$. Other developmental processes regulated by PRKs include organ elongation (ERECTA), floral organ abscission (HAESA), epidermal cell specification (CRINKLY4), postmeiotic pollen development (PRK1), cell elongation (WAK1) and brassinosteroid signalling (BRI1) [5]. Other members of the PRK superfamily such as FLS2 (which is involved in the perception of the bacterial elicitor flagellin) and Xa21 play a role in the plant's defence response $[11,12]$.

\section{Ligands}

The recent identification of several soluble, extracellular ligands represents an important advance in our understanding of PRK function. One of the best characterised of these molecules is the $S$ locus cysteine-rich protein (SCR/SP11 $\left[13^{*}, 14^{*}\right]$ ) which has been shown to interact directly with SRK in vitro $\left[15^{* *}, 16^{*}\right]$. Genetic data, including the highly polymorphic nature of $S C R$, its location at the $S$ (self-incompatibility) locus and the fact that it confers a self-incompatible phenotype to pollen when expressed in transgenic plants, strongly support the contention that SCR is the functional ligand of SRK. 
There is also good evidence that a secreted polypeptide (CLV3), a brassinosteroid (brassinolide) and a fragment of bacterial flagellin proteins are ligands for three additional PRKs: CLV1, BRI1 and FLS2, respectively. In all three cases it has been demonstrated that these receptors are necessary for the binding and perception of their putative ligands $\left[12,17^{* *}, 18^{*}, 19^{*}\right]$. CLV3, for example, binds to yeast cells that co-express CLV1 and CLV2 (a truncated PRK that lacks a kinase domain [20]) and genetic data indicate that CLV1, CLV2 and CLV3 function in the same signalling pathway to control meristem development [21,22]. Finally WAK1, a PRK that is strongly bound to the cell wall, interacts specifically with a glycine-rich extracellular protein, AtGRP-3 [23*]. There is evidence that AtGRP-3 has a signalling role that would be coherent with its acting as a ligand for Wak1.

Assuming some degree of concerted evolution between structurally related PRKs and their respective ligands [24], it is likely that the identification of the molecules described above will facilitate the identification of ligands for other PRKs. Interestingly, two large families of genes that share homology with SCR and CLV3 have been identified recently in the Arabidopsis genome [25,26].

As is the case with receptor kinases in animals, PRK ligands are almost exclusively small, secreted proteins. Brassinolide, which is a steroid, is an exception. Membrane-bound receptors for steroids are also thought to exist in animals, where they have been proposed to mediate non-genomic responses to these molecules, but these receptors have not yet been cloned [27].

\section{Receptor complexes}

PRKs, like their animal counterparts, are associated with other proteins in complexes. CLV1, for example, is associated in vivo with two complexes of $\sim 185$ and $\sim 450 \mathrm{kDa}$ 
[28**]. The $\sim 185 \mathrm{kDa}$ complex probably corresponds to a disulphide-linked CLV1/CLV2 heterodimer [20]. Formation of the $\sim 450 \mathrm{kDa}$ complex requires a functional $C L V 3$ gene indicating that this complex contains the activated form of the receptor $\left[28^{* *}\right]$. The $\sim 450 \mathrm{kDa}$ complex is thought to represent a dimer of the $\sim 185$ kDa CLV1/CLV2 complex plus CLV3 and additional recruited proteins including kinase-associated protein phosphatase (KAPP) and Rop, a Rho/Rac-GTPase-related protein $\left(\left[28^{* *}\right]\right.$, Figure $\left.2 b\right)$.

A similar situation has been described for WAK1 which has been shown, by immunoprecipitation, to associate with its putative ligand, AtGRP-3, and with KAPP [23*]. Two complexes of $\sim 200$ and $\sim 500 \mathrm{kDa}$ were identified, AtGRP-3 and KAPP being associated with the larger complex.

SRK is also associated with high molecular weight, non-covalently linked complexes in vivo. In the absence of pollination, SRK in the plasma membrane of the stigmatic papillar cells is in a basal, inactive state [30*]. In this basal state, SRK is associated with two complexes of $\sim 161$ and $\sim 290 \mathrm{kDa}$ ([29*], D Cabrillac and T Gaude, unpublished data). Recently, cross-linking experiments using ${ }^{125}$ I-labelled SCR ligand identified two ligand-binding proteins of 120 and $65 \mathrm{kDa}$ [16*]. The $120 \mathrm{kDA}$ protein was SRK whilst the $65 \mathrm{kDa}$ protein may have been either eSRK (a soluble, truncated form of SRK produced by alternative splicing [31]) or SLG (a secreted glycoprotein that is highly similar to the extracellular domain of SRK and which is encoded by a gene closely linked to $S R K$ at the $S$ locus). Neither eSRK nor SLG are associated with SRK in the absence of pollination ([29*], D Cabrillac and T Gaude, unpublished data) suggesting that eSRK and/or SLG is recruited to the activated receptor complex following self-pollination (Figure 2a). 
Both the SRK and CLV1 receptor complexes include truncated, receptor-like proteins that are either soluble (eSRK/SLG) or membrane-anchored (CLV2). Interestingly, genetic evidence indicates that binding of flagellin requires the product of a second locus, FLS1, in addition to the LRR receptor kinase FLS2 [32]. The FLS1 gene has not yet been cloned, but it will be interesting to see whether the flagellin receptor and/or other PRK receptor complexes also include truncated PRK receptors. Truncated forms of many animal receptor kinases have been described but, apart from a limited number of studies which indicate that they act as receptor antagonists $[33,34,35]$, their functions in vivo are unclear.

\section{Receptor activation and signal transduction}

Receptor oligomerisation and autophosphorylation are critical steps in the activation of animal receptor kinases of both the RTK and the RSK families [36,37]. Recent studies indicate that PRKs also autophosphorylate in response to ligand binding both in vitro and in vivo $\left[16^{*}, 19^{*}, 30^{*}\right]$ and there is evidence that phosphorylation can occur in trans within receptor oligomers. Using epitope-tagged receptors, transphosphorylation has been demonstrated between SRK molecules in vitro in a membrane environment [29*]. Moreover, the induction of SRK autophosphorylation that is seen following addition of pollen coat proteins (which include the SRK ligand, SCR) can be mimicked by adding a bivalent antibody that recognises the N-terminal end of SRK [30*]. This suggests that SCR, which probably exists as a dimer in vivo [15**], activates SRK by creating bridges between two molecules of the receptor. Note also that the $\sim 450 \mathrm{kDa}$ CLV1 complex was only detected in the presence of CLV3 suggesting that activation of CLV1 also involves oligomerisation. 
Interestingly, mutations that lead to loss of kinase activity in either CLV1 or FLS2 also result in a loss of ligand binding activity $\left[12,17^{* *}\right]$. This phenomenon has not been described for animal receptor kinases and it may be symptomatic of a difference between the mechanisms of activation of receptor kinases in plants and animals. Note, however, that there is evidence that this requirement of kinase activity for ligand binding may not be a general feature of all PRKs [15**].

At present, the only protein that has been shown to be a component of a signal transduction pathway downstream of a PRK is Arm repeat containing 1 (ARC1, Figure 2a). Suppression of ARC1 expression in transgenic Brassica napus plants causes a substantial weakening of the self-incompatibility response mediated by SRK [38*]. Rop, which is associated with the $\sim 450 \mathrm{kDa}$ CLV1 receptor complex, is also thought to be involved in downstream signalling. Plants lack a clear orthologue of Ras and it has been suggested that the related Rop protein activates a downstream MAPK cascade that negatively regulates WUSCHEL expression in the meristem ([39]; compare Figure 2b and d). Several additional, potential signal transduction components have been identified recently using protein-protein interaction, genetic and proteomic approaches $[40,41,42]$.

\section{Fine control of receptor kinase signalling}

In animals, receptor kinases are highly regulated. For example, several mechanisms exist to down-regulate receptor kinase activity including kinase inhibitors, phosphatases and turnover via endocytosis. These processes are only starting to be investigated in plants but some interesting parallels can already be drawn.

In the absence of its ligand, constitutive activation of SRK is prevented by the thioredoxin-h THL1 (and probably also THL2) which binds to a site on the cytosolic 
side of the transmembrane domain that includes a conserved cysteine residue $\left[30^{*}, 43\right]$. This situation is reminiscent of the action of FKBP12 which binds to the GS domain of TGF $\beta$ R-I preventing phosphorylation of this receptor by its partner, TGF $\beta$ R-II [44] (compare Figure 2a and c). THL1 and FKBP12 are unrelated at the sequence level indicating that the two inhibition systems have evolved independently. Interestingly, although thioredoxin has not been shown to interact with animal receptor kinases, it has been reported to inhibit murine p38 MAP kinase [45], suggesting an ancient origin for this type of regulation.

Dephosphorylation by phosphatases is a process that plays an important role in the down-regulation of receptor kinases in both plants and animals. KAPP has been shown to associate with a number of PRKs including CLV1 and FLS2 $\left[18^{*}, 23^{*}, 46,47,48,49\right]$. KAPP is phosphorylated by CLV1 and dephosphorylates the kinase domain of this receptor in vitro $[47,48]$. Experiments in which KAPP expression has been manipulated in transgenic plants indicate that KAPP is a negative regulator of both CLV1 and FLS2 $\left[18^{*}, 47,48\right]$ and it has been proposed that KAPP has a general role in the down-regulation of a large spectrum of PRKs (Figure 2a, b). In animals, phosphatases such as SHP-1 also have a general role in the down-regulation of receptor kinase activity whilst others, such as SHP-2, are components of signal transduction pathways [50] (Figure 2d).

Down-regulation of RTKs following ligand binding involves endocytosis and receptor recycling or degradation. Polyubiquitylation, catalysed by the RING finger protein $\mathrm{Cbl}$ acting as a ubiquitin protein ligase, stimulates endocytosis and downregulation of the epidermal growth factor receptor (EGFR). Interestingly, Cbl, shares several features with the SRK interacting protein, ARC1 (Figure 2a and d). Both Cbl and ARC1 have structures that are characteristic of adapter proteins, with multiple 
protein-protein interaction domains, and both proteins interact only with the phosphorylated state of the kinase domains of their respective receptor interaction partners. Moreover, ARC1 possesses a $\mathrm{U}$ box [51], a domain that is structurally and functionally related to the RING finger domain [52]. The Arabidopsis genome contains 19 genes with a structure similar to ARC1 [51]. Might ARC1 or other members of this family mediate ubiquitylation of PRKs? This may be difficult to reconcile with the evidence that $\mathrm{ARC} 1$ acts as a positive regulator of SRK signalling but note that $\mathrm{Cbl}$ has been shown to have both negative and positive roles in signal transduction [53].

Down-regulation of animal receptor kinases by endocytosis is a slow process taking more than 30 minutes but this process is complemented by more rapid mechanisms involving several cytosolic proteins. One such protein is calmodulin, which binds to both EGFR and the insulin receptor and, at least in the case of EGFR, acts as an inhibitor [54]. Recently, we have shown that calmodulin binds to the kinase domains of several PRKs in vitro but the physiological role of this interaction remains to be elucidated (V.V. and J.M.C., unpublished results).

\section{Conclusion}

Considerable progress has been made in understanding the molecular mechanism of receptor kinase signalling in plants in recent years. One conclusion that can be drawn from these studies is that there are clear differences between receptor kinase signalling in plants and animals. For example, apart from calmodulin, none of the proteins that interact with PRKs are closely homologous to animal receptor kinase interacting proteins. These differences support the hypothesis that receptor kinases have evolved independently in the two kingdoms [1**]. 
Despite these differences between plant and animal receptor kinases, several basic features are shared such as receptor dimerisation, the existence of receptor complexes and certain mechanisms of downregulation. Given the distant relationship between receptor kinases in the two kingdoms, these similarities are of particular interest because they may represent convergently evolved solutions to the same fundamental molecular problems. This is particularly true when similar functions are mediated by unrelated molecules, for example if the inhibition of SRK by thioredoxin is compared with the inhibition of TGF $\beta$ R by FKBP12. With the current acceleration in the pace at which PRKs are being characterised at the molecular level, comparisons of this kind, between plant and animal receptors, will become increasingly informative. In this context, it will be particularly interesting to address new questions that are emerging from studies on animal receptors in plant systems, such as the relationships between ligand binding, dimerisation and receptor activation $\left[55,56^{*}\right]$, the role of receptor localisation in signalling and the mechanism of turnover of activated receptor complexes [57].

\section{Acknowledgements}

We would like to thank Charlie Scutt and Marc Billaud for their comments on the manuscript. JMC is a member of the Institut National de Recherche Agronomique, TG is a member of the Centre National de Recherche Scientifique. We apologise that, due to space limitations, we were not able to refer to many important, earlier papers in this area. 
References and recommended reading

**1. Shiu SH, Bleecker AB: Receptor-like kinases from Arabidopsis form a monophyletic gene family related to animal receptor kinases. Proc Natl Acad Sci USA 2001, 98:10763-10768.

A comprehensive description of the PRK family in Arabidopsis and its evolutionary relationship to animal receptor kinases.

2. Walker JC: Receptor-like protein kinase genes of Arabidopsis thaliana. Plant J 1993, 3:451-456.

3. Hunter T, Plowman GD: The protein kinases of budding yeast: six score and more. TIBS 1997, 22:18-22.

4. Meyerowitz EM: Plants, animals and the logic of development. Trends Cell Biol 1999, 9:M65-M68.

5. Torii KU, Clark SE: Receptor-Like Kinases in Plant Development. In Advances in Botanical Research. thematic volume "Plant Protein Kinases", vol 32. Edited by Kreis M, Walker JC. London: Academic Press; 2000:270-298.

6. Stein JC, Howlett B, Boyes DC, Nasrallah ME, Nasrallah JB: Molecular cloning of a putative receptor protein kinase gene encoded at the self-incompatibility locus of Brassica oleracea. Proc Natl Acad Sci USA 1991, 88:8816-8820. 
7. Takasaki T, Hatakeyama K, Suzuki G, Watanabe M, Isogai A, Hinata K. The $\boldsymbol{S}$ receptor kinase determines self-incompatibility in Brassica stigma. Nature 2000, 403:913-916.

The authors showed that transgenic Brassica plants expressing $\mathrm{SRK}_{28}$ were able to reject pollen from an $S_{28}$ plant demonstrating that SRK is sufficient to mediate haplotype-specific recognition of self-pollen on the female side in the selfincompatibility response. A stronger rejection of pollen was observed when $\mathrm{SLG}_{28}$ was expressed in addition to $\mathrm{SRK}_{28}$ indicating that $\mathrm{SLG}$ also plays a role (directly or indirectly via SRK) in pollen rejection.

**8. Fletcher JC, Brand U, Running MP, Simon R, Meyerowitz EM: Signaling of cell fate decisions by CLAVATA3 in Arabidopsis shoot meristems. Science 1999, 283:1911-1914.

First description of a plant gene encoding a putative receptor kinase ligand. CLV3 was shown to be expressed in a region of the meristem overlying the region of CLVI expression and to encode a small, putatively secreted peptide.

*9. Brand U, Fletcher JC, Hobe M, Meyerowitz EM, Simon R: Dependence of stem cell fate in Arabidopsis on a feedback loop regulated by CLV3 activity. Science 2000, 289:617-619.

See annotation $\left[10^{*}\right]$.

*10. Schoof H, Lenhard M, Haecker A, Mayer KF, Jurgens G, Laux T: The stem cell population of Arabidopsis shoot meristems in maintained by a regulatory loop between the $\boldsymbol{C L A V A T A}$ and $\boldsymbol{W U S C H E L}$ genes. Cell 2000, 100:635-644. 
This paper and [9] describe a feedback loop, involving the $C L V$ genes and $W U S$, which controls meristem size. CLV signalling represses $W U S$ at the transcriptional level whilst WUS expression is required for the induction of $C L V 3$ expression.

11. Song W-Y, Wang G-L, Chen L-L, Kim H-S, Pi L-Y, Holsten T, Gardner J, Wang B, Zhai W-X, Zhu L-H, Fauquet C, Ronald P: A receptor kinase-like protein encoded by the rice disease resistance gene, Xa21. Science 1995, 270:1804-1806.

12. Gomez-Gomez L, Boller T: FLS2: an LRR receptor-like kinase involved in the perception of the bacterial elicitor flagellin in Arabidopsis. Mol Cell 2000, 5:10031011.

*13. Schopfer CR, Nasrallah ME, Nasrallah JB. The male determinant of selfincompatibility in Brassica. Science 1999, 286:1697-1700.

This paper and $\left[14^{*}\right]$ describe the identification of the SRK ligand SCR/SP11. $S C R / S P 11$ is shown to encode the male component of the self-incompatibility response in Brassica by two different methods: 1) a transgenic gain-of-function / loss-of-function approach (this paper) and 2) a bioassay involving the application of the protein to stigmatic papillae before pollination [14*].

*14. Takayama S, Shiba H, Iwano M, Shimosato H, Che FS, Kai N, Watanabe M, Suzuki G, Hinata K, Isogai A: The pollen determinant of self-incompatibility in Brassica campestris. Proc Natl Acad Sci USA 2000, 97:1920-1925.

See annotation for [13*]. 
**15. Kachroo A, Schopfer CR, Nasrallah ME, Nasrallah JB: Allele-specific receptorligand interactions in Brassica self-incompatibility. Science. 2001, 293:1824-1826.

SCR was shown to interact with the extracellular domain of SRK in vitro in an haplotype-specific manner. A weaker, but again haplotype-specific, interaction was also detected between SCR and a $\sim 65 \mathrm{kDa}$ protein corresponding to SLG (or perhaps eSRK?). Under non-reducing conditions SCR migrated as an $\sim 16 \mathrm{kDa}$ band indicating homodimerisation.

*16. Takayama S, Shimosato H, Shiba H, Funato M, Che FS, Watanabe M, Iwano M, Isogai A: Direct ligand-receptor complex interaction controls Brassica selfincompatibility. Nature. 2001, 413:534-538.

Crosslinking was used to show that SP11 (SCR) interacts both with SRK and with either eSRK or SLG when added to microsomes prepared from stigmas.

**17. Trotochaud AE, Jeong S, Clark SE: CLAVATA3, a multimeric ligand for the CLAVATA1 receptor-kinase. Science 2000, 289:613-617.

This paper provided the first biochemical evidence for an interaction between a PRK (CLV1) and its putative ligand (CLV3). CLV3 was shown to bind to yeast cells expressing CLV1 and CLV2 and to be part of a complex that included CLV1 in vivo.

*18. Gomez-Gomez L, Bauer Z, Boller T: Both the extracellular leucine-rich repeat domain and the kinase activity of FLS2 are required for flagellin binding and signaling in Arabidopsis. Plant Cell 2001, 13:1155-1163.

Point mutations in both the extracellular domain and the kinase domain of FLS2 resulted in reduced flagellin binding activity in cellular extracts, suggesting that kinase 
activity is required for ligand binding. Overexpression of KAPP, which was shown to interact with the FLS2 kinase domain in the yeast two hybrid system, resulted in reduced sensitivity of transgenic plants to flagellin indicating a role as a negative regulator.

*19. Wang ZY, Seto H, Fujioka S, Yoshida S, Chory J: BRI1 is a critical component of a plasma-membrane receptor for plant steroids. Nature. 2001, 410:380-383.

The authors showed that over-expression of BRI1 in transgenic plants both increased cell elongation (a physiological response to brassinolide) and increased the density of brassinolide binding sites in membrane fractions prepared from the transgenic plants. Brassinolide was shown to be associated with BRIl in a complex by immunoprecipitation from tissue extracts and mutations in the extracellular domain of BRI1 disrupted this association.

20. Jeong S, Trotochaud AE, Clark SE: The Arabidopsis CLAVATA2 gene encodes a receptor-like protein required for the stability of the CLAVATA1 receptor-like kinase. Plant Cell 1999, 11:1925-1934.

CLV2 was shown to encode a PRK-like protein with an extracellular domain, a membrane-spanning domain but only a short cytoplasmic tail. CLV2 is required for normal accumulation of CLV1 and its assembly into protein complexes indicating that CLV2 may form a covalently-linked heterodimer with CLV1.

21. Clark SE, Running MP, Meyerowitz EM: CLAVATA3 is a specific regulator of shoot and floral meristem development affecting the same processes as CLAVATA1. Development 1995, 121:2057-2067. 
22. Kayes JM, Clark SE: CLAVATA2, a regulator of meristem and organ development in Arabidopsis. Development. 1998, 125:3843-3851.

*23. Park AR, Cho SK, Yun UJ, Jin MY, Lee SH, Sachetto-Martins G, Park OK: Interaction of the Arabidopsis Receptor Protein Kinase Wak1 with a Glycine-rich Protein, AtGRP-3. J Biol Chem 2001, 276:26688-26693.

Several members of the Wak family of PRKs were shown to interact specifically with AtGRP-3 (and not with other members of the Arabidopsis GRP family). Receptor complexes that included Wak1 were characterised.

24. Fryxell KJ: The coevolution of gene family trees. Trends Gen 1996, 12:364-369.

25. Vanoosthuyse V, Miege C, Dumas C, Cock JM: Two large Arabidopsis thaliana gene families are homologous to the Brassica gene superfamily that encodes pollen coat proteins and the male component of the self-incompatibility response. Plant Mol Biol 2001, 46:17-34.

26. Cock JM, McCormick S. A large family of genes that share homology with CLAVATA3. Plant Physiol 2001, 126:939-942.

27. Schmidt BM, Gerdes D, Feuring M, Falkenstein E, Christ M, Wehling M: Rapid, nongenomic steroid actions: A new age? Front Neuroendocrinol 2000, 21:57-94. 
**28. Trotochaud AE, Hao T, Wu G, Yang Z, Clark SE: The CLAVATA1 receptorlike kinase requires CLAVATA3 for its assembly into a signaling complex that includes KAPP and a Rho-related protein. Plant Cell 1999, 11:393-406.

The authors show that CLV1 is associated with two complexes of $\sim 185$ and $\sim 450 \mathrm{kDa}$ in vivo. The $\sim 450$ complex included KAPP and Rop and required a functional CLV3 gene for its assembly.

*29. Giranton JL, Dumas C, Cock JM, Gaude T: The integral membrane $S$ locus receptor kinase of Brassica has serine/threonine kinase activity in a membranous environment and spontaneously forms oligomers in planta. Proc Natl Acad Sci USA 2000, 97:3759-3764.

Using epitope-tagged, recombinant SRK proteins expressed in insect cells, SRK was shown to autophosphorylate in trans in a membrane environment. Cross-linking and sedimentation gradient experiments showed that SRK is associated with higher molecular weight complexes in planta.

*30. Cabrillac D, Cock JM, Dumas C, Gaude T. The $S$-locus receptor kinase is inhibited by thioredoxins and activated by pollen coat proteins. Nature 2001, 410:220-223.

SRK was shown to be phosphorylated one hour after a self-incompatible pollination. Autophosphorylation of SRK was inhibited in vitro by a stigma thioredoxin, THL1, and this inhibition was released by addition of a mixture of pollen coat proteins which putatively included the SRK ligand. 
31. Giranton JL, Ariza MJ, Dumas C, Cock JM, Gaude T: The $\boldsymbol{S}$ locus receptor kinase gene encodes a soluble glycoprotein corresponding to the SRK extracellular domain in Brassica oleracea. Plant $J$ 1995, 8:827-834.

32. Bauer Z, Gómez-Gómez L, Boller T, Felix G: Sensitivity of Different Ecotypes and Mutants of Arabidopsis thaliana Towards the Bacterial Elicitor Flagellin Correlates with the Presence of Receptor Binding Sites. J Biol Chem 2001, in press. A flagellin binding assay was used to correlate the presence of a high affinity binding site with induction of flagellin-dependant responses. Analysis of mutants indicated that the products of both the FLS1 and FLS2 genes are required for the formation of a functional, high-affinity flagellin binding site.

33. Duan D-SR, Pazin MJ, Fretto LJ, Williams LT: A functional soluble extracellular region of the platelet-derived growth factor (PDGF) receptor antagonizes PDGFstimulated responses. $J$ Biol Chem 1991, 266:413-418.

34. Flickinger TW, Maihle NJ, Kung H-J: An alternatively processed mRNA from the avian c-erbB gene encodes a soluble, truncated form of the receptor that can block ligand-dependant transformation. Mol Cel Biol 1992, 12:883-893.

35. Onichtchouk D, Chen YG, Dosch R, Gawantka V, Delius H, Massague J, Niehrs C: Silencing of TGF-beta signalling by the pseudoreceptor BAMBI. Nature 1999, 401:480-485. 
36. Massagué J, Blain SW, Lo RS: TGF $\beta$ Signaling in Growth Control, Cancer, and Heritable Disorders. Cell 2000, 103:295-309.

37. Schlessinger J: Cell signaling by receptor tyrosine kinases. Cell 2000, 103:211225.

*38. Stone SL, Arnoldo M, Goring DR: A breakdown of Brassica selfincompatibility in $\boldsymbol{A R C 1}$ antisense transgenic plants. Science 1999, 286:1729-1731. Transgenic Brassica plants in which ARCl expression was suppressed exhibited a reduced ability to reject self-pollen and set more seed than wild-type control plants indicating a positive role for ARC1 in the signal transduction pathway that initiates selfpollen rejection.

39. Clark SE: Cell signalling at the shoot meristem. Nat Rev Mol Cell Biol 2001, 2:276-284.

40. Li J, Lease KA, Tax FE, Walker JC: BRS1, a serine carboxypeptidase, regulates BRI1 signaling in Arabidopsis thaliana. Proc Natl Acad Sci USA 2001, 98:5916-5921.

41. Peck SC, Nuhse TS, Hess D, Iglesias A, Meins F, Boller T: Directed proteomics identifies a plant-specific protein rapidly phosphorylated in response to bacterial and fungal elicitors. Plant Cell 2001, 13:1467-1475.

42. Skirpan AL, McCubbin AG, Ishimizu T, Wang X, Hu Y, Dowd PE, Ma H, Kao Th: Isolation and Characterization of Kinase Interacting Protein 1, a Pollen Protein 
That Interacts with the Kinase Domain of PRK1, a Receptor-Like Kinase of Petunia. Plant Physiol 2001, 126:1480-1492.

43. Mazzurco M, Sulaman W, Elina H, Cock JM, Goring DR: Further analysis of the interactions between the Brassica $S$ receptor kinase and three interacting proteins (ARC1, THL1 and THL2) in the yeast two-hybrid system. Plant Mol Biol 2001, 45:365-376.

44. Wang T, Li BY, Danielson PD, Shah PC, Rockwell S, Lechleider RJ, Martin J, Manganaro T, Donahoe PK: The immunophilin FKBP12 functions as a common inhibitor of the TGF beta family type I receptors. Cell 1996, 86:435-44.

45. Hashimoto S, Matsumoto K, Gon Y, Furuichi S, Maruoka S, Takeshita I, Hirota K, Yodoi J, Horie T: Thioredoxin negatively regulates p38 MAP kinase activation and IL-6 production by tumor necrosis factor-alpha. Biochem Biophys Res Commun 1999, 258:443-447.

46. Braun DM, Stone JM, Walker JC: Interaction of the maize and Arabidopsis kinase interaction domains with a subset of receptor-like protein kinases: implications for transmembrane signaling in plants. Plant $J 1997,12: 83-95$.

47. Williams RW, Wilson JM, Meyerowitz EM. A possible role for kinase-associated protein phosphatase in the Arabidopsis CLAVATA1 signaling pathway. Proc Natl Acad Sci USA. 1997, 94:10467-10472. 
This paper and [48] used transgenic plants over- and under-expressing KAPP to show that this protein phosphatase acts as a negative regulator of CLV1 in vivo. The kinase domain of CLV1 was also shown to bind to and phosphorylate KAPP and to be dephosphorylated by KAPP in vitro.

48. Stone JM, Trotochaud AE, Walker JC, Clark SE: Control of Meristem Development by CLAVATA1 Receptor Kinase and Kinase-Associated Protein Phosphatase Interactions. Plant Physiol 1998, 117:1217-1225.

See annotation [47].

49. van der Knaap E, Song WY, Ruan DL, Sauter M, Ronald PC, Kende H: Expression of a gibberellin-induced leucine-rich repeat receptor-like protein kinase in deepwater rice and its interaction with kinase-associated protein phosphatase. Plant Physiol 1999, 120:559-570.

50. Ostman A, Bohmer FD: Regulation of receptor tyrosine kinase signaling by protein tyrosine phosphatases. Trends Cell Biol 2001, 11:258-266.

51. Azevedo C, Santos-Rosa MJ, Shirasu K: The U-box protein family in plants. Trends Plant Sci 2001, 6:354-358.

52. Aravind L, Koonin EV: The $\mathbf{U}$ box is a modified RING finger - a common domain in ubiquitination. Curr Biol 2000, 10:R132-R134. 
53. Thien $\mathrm{CB}$, Langdon WY: Cbl: many adaptations to regulate protein tyrosine kinases. Nat Rev Mol Cell Biol 2001, 2:294-307.

54. San Jose E, Benguria A, Geller P, Villalobo A: Calmodulin inhibits the epidermal growth factor receptor tyrosine kinase. J Biol Chem 1992, 267:15237-15245.

55. Jiang G, Hunter T: When dimerization is not enough. Curr Biol 1999, 9:R568R517.

A review of evidence that receptor activation may require specific intersubunit conformation changes in addition to receptor dimerisation.

*56. Verveer PJ, Wouters FS, Reynolds AR, Bastiaens PIH: Quantative Imaging of Lateral ErbB1 Receptor Signal Propagation in the Plasma Membrane. Science 2000, 290:1567-1570.

Frequence resonance energy transfer (FRET) between fluorescently-tagged ErbB1 and anti-phosphotyrosine molecules was used to show that receptors were activated across the surface of a cell in a wave-like and ligand-independent manner following local activation with immobilised ligand.

57. Carraway III KL, Sweeney C: Localization and modulation of ErbB receptor tyrosine kinases. Curr Opin Cell Biol 2001, 13:125-130.

A review of the many factors that modulate ErbB receptor kinase signalling, including a discussion of recent studies that have demonstrated the importance of receptor localisation. 


\section{Figure 1}

Model for the evolution of the receptor kinase superfamily based on a comparison of kinase domain sequences $\left[1^{* *}\right]$. Dark colours represent receptor kinase lineages, light colours represent related (homologous), cytosolic kinases. The arrowhead indicates the point at which the plant and animal lineages diverged.

\section{Figure 2}

Schema showing some of the features of inactive and ligand activated receptor kinase complexes in plants and animals. The colours highlight similarities between plant and animal receptor kinase complexes such as basal-state inhibitors (orange), phosphatases, (green), small G proteins (grey) and RING finger/U-box proteins (red). Association of KAPP and Rop with the plasma membrane has not been demonstrated experimentally. Red arrows indicate phosphorylation (P) and/or activation; red bars indicate dephosphorylation and/or inhibition. ARC1 possesses an ARM repeat region (A), a Ubox (U) and a leucine zipper (Z); Cbl has a proline-rich domain (PR), a RING finger domain $(\mathrm{R})$ and a TKB domain.

\section{Keywords}

Dimerisation, ligand, phosphatase, phosphorylation, plant receptor kinase, signal transduction 